\title{
A Review on Design \&Analysis of Lancashire Boiler
}

\author{
R.V.Sanga \\ Department of Mechanical Engineering \\ N. K. Orchid college of Engg. \& Tech., Solapur, Maharashtra, India \\ C.V.Papade \\ Department of Mechanical Engineering \\ N. K. Orchid college of Engg. \& Tech., Solapur, Maharashtra, India \\ Dr.B.K.Sonage \\ Department of Mechanical Engineering \\ N. K. Orchid college of Engg. \& Tech., Solapur, Maharashtra, India
}

\begin{abstract}
This review paper is comprehensive study of design and analysis of Lancashire Boiler. Now a day's energy is very important and it should not be wasted. Lancashire Boiler is a stationary, fire tube, internally fired, horizontal and natural circulation boiler. Lancashire boilers are reliable and bear over load. However, they are bulky and initially raise steam very slowly. Many of the researcher's has developed fire-tube boiler based on the mass, energy, and momentum balances together with constitutional equations. The performances of fire tube are effective when running with different fuels. Working pressure in Lancashire boilers are in the range of $0.7 \mathrm{MPa}$ to $2 \mathrm{MPa}$ and efficiency of the boiler is about $65 \%-70 \%$. Today the main concern is to increase the efficiency of Lancashire boiler by enhancing the heat transfer rate in the boiler tube. Due to economic and environment demand, engineers must continuously focus on improving the efficiency of the boiler and reducing emission. Wide variety of engineering situations, including heat exchangers for viscous liquids in chemical process and food industry. Boiler reliability, safety and usability are crucial for power plants. Boilers and components in hot conditions, such as wall tubes, cylinders, valves and channels have a limited lifespan; therefore preventive condition monitoring is very important. Dye penetrant test, radiography test, stress relief test \& hydro test are the basically main testing of boiler while manufacturing. These testing will give always prevent boiler bursting or any accidents regarding boiler, So these are the necessary testing for boiler.
\end{abstract}

Keywords: - Fire tube boiler, Lancashire boiler, Heat transfer, Emission, Methods of testing.

\section{INTRODUCTION}

A fire tube boiler is a type of boiler in which hot gases from a fire passes through one or more tubes running through a sealed container of water. The heat of the gases is transferred through the walls of the tubes by thermal conduction, heating the water and ultimately creating steam. The fire-tube boiler developed as the third of the four major historical types of boilers low-pressure tank or "haystack" boilers, flued boilers with one or two large flues, fire tube boilers with many small tubes, and high-pressure water-tube boilers. Their advantage over flued boilers with a single large flue is that the many small tubes offer far greater heating surface area for the same overall boiler volume. The general construction is as a tank of water penetrated by tubes that carry the hot flue gases from the fire. The tank is usually cylindrical for the most part being the strongest practical shape and this cylindrical tank may be either horizontal or vertical. The process of designing the Lancashire boiler involves developing a conceptual physical geometry, making necessary calculations from which dimensions and other deductions can be made, and finally, developing a working drawing, analyzing with software. There are several researchers working on fire tube boiler and its efficiency. As per the present market condition, there are few fire tube which can be used for steam generation. So the efficiency of Lancashire boiler can be analyzed with the help of performance parameters and this analysis can be used for improvement of boiler efficiency.

Lancashire boiler is one of the type of fire tube boiler, it is horizontal smoke tube boiler with single furnace and three pass boiler. It is placed in horizontal position over a brick work or saddle support it is partly filled up with water. The water level inside the shell is well above the furnace tubes 


\section{LITERATURE REVIEW}

1. M. A. Waheed et al.[1], The laboratory steam boiler designed was projected from the conceptual physical geometry of fire-tube boiler which elucidated the primary units making up a boiler. Thermodynamics, heat transfer and strength of materials analysis subjected to temperature and pressure variations were conducted in the theoretical framework of the laboratory fire-tube steam boiler. Dimensions of major and secondary parts were estimated from computations from the theoretical framework and 3D modelling process for the steam boiler was then carried out to present various working drawings of the steam boiler for possible construction. Conclusively, a simple laboratory fire tube steam boiler is herein presented for fabrication, testing and further improvement. Production of a simple steam boiler of this sort will enable the availability of portable and affordable steam boilers for steam generation processes, especially in school laboratories.

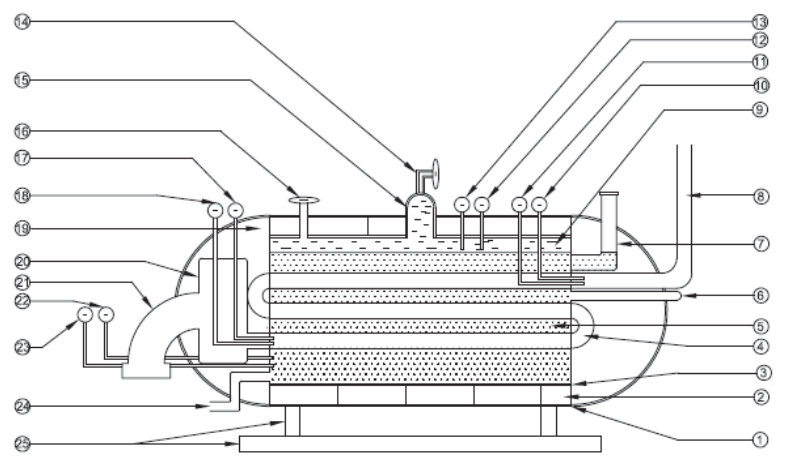

Fig.1 Cross section view of steam boiler

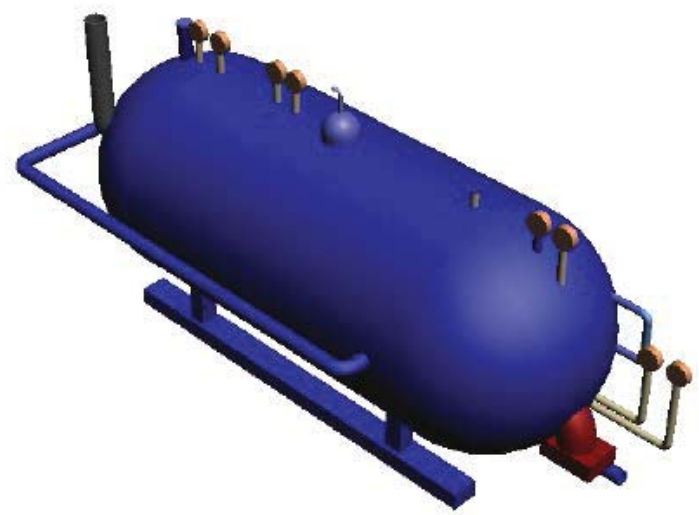

Fig. 2 Isometric view of steam boiler

2. F.J. Gutiérrez et al. [2], A complete dynamic model of a full-scale fire-tube boiler has been developed based on the mass, energy, and momentum balances together with constitutional equations. Two parts are distinguished in fire-tube boilers: the fire/gas side and the water/ steam side. A first nonlinear physical model has been presented and after reduced to shorten the computational time, but providing reasonable results. The boiler start-up has been also taken into account. Thus, it may allow to simulate the process as well as to design a multivariable controller. Simulation is useful both for training and assisting in on-line decisions. A case study has been simulated using an $800 \mathrm{HP}$ fire-tube boiler and dynamic performances predicted by the model are in good qualitative agreement with data taken from the literature. The proposed modeling may be used as an effective way of undertaking a comparison between the fire-tube boiler performances when running with different fuels, especially when considering the firing of a new fuel in given equipment.

3 N. Samaras et al.[3], Simulation and optimization results of a $300 \mathrm{MW}$ lignite-fired power plant were presented. To reduce the computational time needed the creation of the modules in gPROMS FO (Foreign Objects) for the calculations of thermodynamic and heat transfer properties of the fluids was important. Use of the FOs, reduced the number of variables to 10,906 from 375,630 , the number of equations from 333,983 to 10,667 and the number of the parameters of the model. After satisfactory simulating the complete plant we optimized its operation to improve the efficiency while maintaining the same electrical power production. The results showed an absolute improvement of $0.55 \%$ of the overall thermal efficiency which is important for plants of that size since the resulting benefits were lower fuel consumption.(2.06\% reduction which means $11.5 \mathrm{t} / \mathrm{h}$ less lignite), and lower flue gas emissions(2.06\%reduction which means $4.8 \mathrm{t} / \mathrm{h}$ less $\mathrm{CO} 2)$. That reduction results to lower penalty fees for environmental pollution This work could lead to the creation of a decision tool for the control room of the unit where the model, through the use of real time data, will allow the engineer in charge to make instant.

4. P. Kumar et al. [4], Pressure vessels are always works under certain pressure and temperature along with contain sometime lethal substances which are hazardous for both human and environment. Considering this, safety implications and hazards arising from the operation of pressure vessels, there is an obvious need to standardize 
engineering and fabrication practices. To assure minimum safety standards, several design codes have prepared and developed. Design of pressure vessel can be finished quickly by applying numerous calculations in software. The drawing process was simpler associated to the software. This study only investigated a part of parameters design. There are other parameters that are not considered such as thermal loads, wind loads, seismic load, transportation load, erection load and fabrication methods etc. however this insufficiency can be overcome by mastering software. Mechanical design of pressure vessel had been done using graphical based software. Drawing process was very easy and input can be entered in the same screen. The result fully complied with standard code and had been employed on practical design of pressure vessel.

5. P. Negi et al.[5], Boiler provides the major source in industries to burn fuel to generate process steam and electric power. It is the main device of power plant to generate steam by efficiently burning available fuels used to generation of power. There are mainly two types of boiler, water tube boiler and fire tube boiler. Water tube boiler are those types in which water flows inside the boiler tube and flue gases flows outside to heat up the water to generate steam. Most industrial purpose uses water tube boiler as it is more efficient than fire tube boiler. Today the main concern is to increase the efficiency of water tube boiler by enhancing the heat transfer rate in the boiler tube. Due to economic and environment demand, engineers must continuously focus on improving the efficiency of the boiler and reducing emission. wide variety of engineering situations, including heat exchangers for viscous liquids in chemical process and food industry. In real condition the boiler water tube are plane walled, due to this the flow inside the tube is laminar. Many studies have focused on turbulent flow, the laminar range is of particular interest in a review of corrugated geometry of boiler tubes, heat transfer studies for different geometries and other various designs are carried out. The researcher's designs going to the integration between the geometry and flow through the tube to reduce heat loss and system costs

6. J. Ganan et al.[6], In general, thermal power installations emit various polluting matter to the atmosphere that contribute to the greenhouse effect and the deterioration of the environment. The main pollutants emitted to the atmosphere in these equipment are Carbon monoxide (CO), Hydrocarbon (HC), Nitrogen Oxides (NOx), Carbon dioxide (CO2) and Sulphur Oxide (SO2). Due to the high contamination of these gases, environmental agencies impose some maximum emission levels. The emission of pollutants has its origin in the resulting gases of the combustion process. Three fundamental elements can be found in this process: fuel, comburent and activation energy. In this study the evaluation of the optimum operation conditions for two three-stage pirotubular boilers, connected in parallel and using gasoil $\mathrm{C}$ is developed. This trade-off defines a maximum of the efficiency in the range of the boiler, in view of Eq. (2) the increase in the losses for sensible heat in the exhaust fumes have menor influence on the boiler efficiency than the decrease of the losses for unburned gases in the exhaust fumes. The efficiency of the boiler is obtained as a function of the losses qA and qi, by using the The TESTO model 300 M-I analyser whose probe was placed at the exit of the boiler.

7. G.A. Ikechukwu [7], The fabricated fire tube boiler was tested to evaluate its performances, efficiency and determine its evaporation ratio. The purpose of the performance test is to determine the actual performance and efficiency of the oiler and compare it with design values or norms. It is an indicator for tracking day-to-day and season-to-season variations in boiler efficiency and energy efficiency improvements. The result in this case is a torque produced at a steam pressure of $1.5 \mathrm{bar}$ and a steam temperature of $111.4^{0} \mathrm{C}$ also raising the temperature of the water from $300 \mathrm{C}$ to a generated steam quantity of $61.34 \mathrm{~kg} / \mathrm{hr}$, with a diesel quantity of $5.2 \mathrm{Htres} / \mathrm{hr}$. The efficiency of the burner after getting an adequate combustion air/fuel ratio and heat delivery from the burner resulted into $64.3 \%$. The efficiency of the boiler was also calculated to be $69 \%$. The following conclusions can be drawn from the data and research that has been mentioned in this paper. Dimensions of major and secondary parts were estimated from computations from the theoretical framework and 3D modelling process for the steam boiler was then carried out to present various working drawings of the steam boiler for possible construction. Good boiler design practices must take into account the operation of the boiler and not simply the heat transfer, parameters that a good boiler design addresses include; a. sample furnace volume must be included to absorb a) significant portion of Radiative heat transfer and allow the low NOx burner designs to function. b.) Optimized pressure drop across the boiler convective passes, the pressure drop determines the fan size required for the boiler application. c.) Ample steam storage and steam height. The volume of steam and distance from the steam nozzle to the normal water level determine to a very large extent the steam quality and the amount of water that will be carried over into the system. Boiler design and optimization programs have been written to determine the performance of fire-tube boilers. These programs can be applied to analyse a wide variety of the boiler scenarios for many different boiler applications extending from simple gas fired systems to complex waste heat applications. Gas temperatures measured at the entrance to the convective tube surfaces provided excellent data that validated the heat transfer sub-models 
augmented surface tubes have proven to be a valuable resource in the design of fire-tube boilers for many special applications. Using the augmented tube also allows the designer to have a lower overall pressure drop with a boiler efficiency that is still over $81 \%$.

8. R.G. Hocker et.al [8]:- Dye penetrant indications on the heat-affected zone of 2014-T6 aluminum weldments have caused many rejections of production assemblies. An investigation of this problem has revealed that a large majority of these indicated defects were superficial in that they were less than $0.007 \mathrm{in}$. deep. Tests were conducted to determine the cause and nature of the surface defects. Procedures were developed to eliminate or minimize the occurrence of dye penetrant indications, and to discriminate between real weld defects and superficial surface defects. Also, procedures were developed for repairing weldments containing dye penetrant indications.

9. N.B. Yahia et.al.[9]:- Radiography is a method of evaluation and non-destructive control. Given the relevance of radiographic inspection of many different areas of industries, there has been numerous research projects aimed at automating the analysis and the interpretation of welding discontinuities. In this work, the automatic control and inspection of welding defects is made by edge detection method of radiographic images, based essentially on the use of a Multilayer Perceptron (MPC). This paper describes an origin method to detect welding defects existing in the weld radiography based in the use of the artificial neural networks, aim the classification and the increase of the successful recognition default percentage. Therefore this work is done in four steps: the first step consist in the preparation of the database to be used later in the second step for training MPC. The next step is done in two main parts; the first part is devoted to the detection of contours, then the second section consists in the elimination of additional contours. Finally, it concludes with on real cases study.

\section{LANCASHIRE BOILER}

A fire-tube boiler is a type of boiler in which hot gases from a fire pass through one or (many) more tubes running through a sealed container of water. The heat of the gases is transferred through the walls of the tubes by thermal conduction, heating the water and ultimately creating steam. The fire-tube boiler developed as the third of the four major historical types of boilers: low-pressure tank or "haystack" boilers, flued boilers with one or two large flues, fire-tube boilers with many small tubes, and high-pressure water-tube boilers. Their advantage over flued boilers with a single large flue is that the many small tubes offer far greater heating surface area for the same overall boiler volume. The general construction is as a tank of water penetrated by tubes that carry the hot flue gases from the fire. The tank is usually cylindrical for the most part being the strongest practical shape and this cylindrical tank may be either horizontal or vertical. The process of designing the fire-tube steam boiler involves developing a conceptual physical geometry, making necessary calculations from which dimensions and other deductions can be made, and finally, developing a working drawing, analyzing with software. There are several researchers working on fire tube boiler and its efficiency. As per the present market condition, there are few fire tube which can be used for steam generation. So the Lancashire boiler can be analyzed with the help of software and this analysis can be used for improvement of boiler.

\section{METHODS OF LANCASHIRE BOILER TESTING}

The boiler shall satisfactorily withstand such pressure without appreciable leakage or undue deflection or distortion of its parts for at least ten consecutive minutes. If the test is not satisfactory, the working pressure allowable by calculation shall be suitably reduced, unless the owner desires to make such alterations as will enable the boiler to withstand satisfactorily the hydraulic test, in which case the boiler shall again be examined after the alterations have been made, the pressure recalculated, if necessary, and the boiler tested to the satisfaction of the Inspector The biggest challenge for boilers is them wearing out, developing, for example, cracks and . Advanced and reliable nondestructive testing (NDT) methods are an essential part of our solution. I For example, latest applications can be used during normal operations, which enables us to find damage mechanisms and produce valuable information immediately without stopping business activities.

With the help of westiong one can plan ahead, prevent the defects from reoccurring, have inspections when it is suitable and use the boiler safely for the next usage period. With careful planning and project management we can target upgrades precisely and carry out projects both time and cost efficiently. Welding method qualification tests can be done in any NDT laboratory. Boiler reliability, safety and usability are crucial for power plants. Boilers and components in hot conditions, such as wall tubes, cylinders, valves and channels have a limited lifespan; therefore preventive condition monitoring is very important. To take the right action at the right time and to optimize the use 
of boilers means preventing leaks, accidents and interruptions for the sake of safety, the environment and maximal uptime. Inspection helps customers to identify and detect potential failures early and to target replacement activities to the right places.

There are some methods of testing which will be used while manufacturing of the boiler. As follows

a) Dye Penetrant Test (DP) is a widely applied and low-cost inspection method used to locate surface-breaking defects in all non-porous materials (metals, plastics, or ceramics). The penetrant may be applied to all non-ferrous materials and ferrous materials, although for ferrous components magnetic-particle inspection is often used instead for its subsurface detection capability.

b)Radiographic Testing (RT), or industrial radiography, is a nondestructive testing (NDT) method of inspecting materials for hidden flaws by using the ability of short wavelength electromagnetic radiation (high energy photons) to penetrate various materials. Either an X-ray machine or a radioactive source, like Ir-192, Co-60, or in rarer cases Cs-137 are used in a X-ray computed tomography machine as a source of photons.

c)Stress Relief Analysis A stress analysis shall be performed to determine if the tank may be exposed to excessive loadings during the mechanical stress relief process. This analysis should include consideration of the local stresses in way of saddles or other supporting structure and additional bending stresses due to the weight of the pressurizing liquid particularly in areas of high stress concentration. While it is necessary that the general stress level during d)Hydro Test is a way in which pressure vessels such as pipelines, plumbing, gas cylinders, boilers and fuel tanks can be tested for strength and leaks. The test involves filling the vessel or pipe system with a liquid, usually water, which may be dyed to aid in visual leak detection, and pressurization of the vessel to the specified test pressure.

\section{CONCLUSION}

The present review of design and analysis of Lancashire boiler draws the following facts. Comparison between the fire-tube boiler performances when running with different fuels, especially when considering the firing of a new fuel in given equipment. Another application may be the tests facilities used in research projects dealing with oxycombustion process. The results showed an absolute improvement of the overall thermal efficiency which is important for plants of that size since the resulting benefits were lower fuel consumption. Boilers and components in hot conditions, such as wall tubes, cylinders, valves and channels have a limited lifespan; therefore preventive condition monitoring is very important. To take the right action at the right time and to optimize the use of boilers means preventing leaks, accidents and interruptions for the sake of safety.

\section{REFERENCES}

[1] I. O. Ohijeagbon, M. A. Waheed, S. O. Jekayinfa, O. E. Opadokun, "Developmental design of a laboratory fire tube steam boiler", ACTA corviniensis-bulletin of engineering tome, Vol. VI, ISSN 2067-3809, 2013

[2] F.J. Gutiérrez Ortiz, "Modelling of fire-tube boilers", Applied Thermal Engineering, Vol. 31, 3463-3478. 2011

[3] G.Tzolakis ,P.Papanikolaou ,D. Kolokotronis , N.Samaras, A.Tourlidakis, A.Tomboulides, , "Simulation of a coal-fired power plant using mathematical programming algorithms in order to optimize its efficiency", 48, 256-267, 2012.

[4] V. Kumar, P. Kumar, "Mechanical design of pressure vessel by using PV-ELITE software", 2014, International Journal of Scientific and Research Publications, Vol. 4, Issue 4,1 ISSN 2250-3153, 2014

[5] P. Negi, Dr. A. Gupta, V. Kumar, "A Review: Heat Transfer Enhancement in Boiler Tube Using Different Geometry", International Journal of Innovative Science, Engineering \& Technology, Vol. 1 Issue 9, ISSN 2348 - 7968, 2014.

[6] J. Gañan, A. Al-Kassir, J.F. Gonza'lez, J. Turegano, A.B. Miranda, "Experimental study of fire tube boilers performance for public heating", Applied Thermal Engineering 25, 1650-1656, 2005.

[7] G. A. Ikechukwu, , "Fabrication of Pilot Multi-Tube Fire-Tube Boiler Designed For Teaching and Learning Purposes in Mechanical Laboratory", Proceedings of the World Congress on Engineering Vol 2, ISSN: 2078-0966, 2014.

[8] R.G.Hocker, Wilson K. R. "Dye penetrant indications caused by superficial surface detects in aluminum alloy welds", 2014.

[9] N.M. Muhaisen, Rajab Abdullah Hokoma, "Calculating the Efficiency of Steam Boilers Based on Its Most Effecting Factors: A Case Study”, Engineering and Technology Vol:6, 03-26, 2012. 